\title{
In vivo CNS Activity of Methanolic Extract of Ficus racemosa Fruits in Experimental Animals
}

\author{
Mst. Shirajum Munira, Md. Shariful Islam, Md. Baharuddin and \\ Sabiha Ferdowsy Koly
}

\author{
Department of Pharmacy, Southeast University, Banani, Dhaka-1213, Bangladesh
}

(Received: 1 April, 2018; Accepted: 12 June, 2018; Published: 31 July, 2018)

\begin{abstract}
The purpose of the study was to evaluate the CNS activity of the methanolic extract of Ficus racemosa fruits. The powdered fruits of $F$. racemosa were extracted with methanol to investigate the effect on central nervous system in Swiss albino mice. The CNS depressant activity was evaluated by observing the reduction of locomotor activity by open field and hole cross tests. The anti-depressant activity was tested by forced swimming and tail suspension methods. For CNS activity, two test doses of the extracts such as 200 and $400 \mathrm{mg} / \mathrm{kg}$ body weight were used. However, the extracts showed significant dose dependent CNS depressant activity when compared to the control in animal models. From our research, it can be concluded that the methanolic extract of $F$. racemosa fruits possesses significant CNS depressant activity. So, further studies are recommended for the isolation of compounds responsible for this activity.
\end{abstract}

Kew words: CNS depressant activity, Ficus racemosa, methanolic extract, locomotor activity.

\section{Introduction}

Ficus racemosa Linn (Family: Moraceae) has been widely used in traditional medicine for a widespread range of diseases. Its fruits, bark, leaves, roots, latex and seeds are medicinally used in different forms (Aiyegoro et al., 2009). The fruits arise from the main trunk, in large clusters, $2-5 \mathrm{~cm}$ in diameter, pyriform and the fruits become figs-like and are green when raw, turning orange and dull reddish. The fruits contain lupeol acetate, $\beta$-sitosterol, hentriacontane, gluanol acetate and tiglic acid ester of taraxasterol and glucose (Deep et al., 2013). The fruits are used as a remedy for the disease of kidney, spleen and dry cough. It is also used as a styptic, astringent and carminative as well as in the treatment of blood disorder, burning sensation, fatigue, urinary discharges, intestinal worms, leucorrhoea, miscarriage, menorrhagia, spermatorrhoea, cancer, scabies, haemoptysis and visceral obstructions
(Vedavathy et al., 1995; Nadkarni et al., 1954; Sharma et al., 2008). The bark 0.5-1.8 cm thick, greyish green, inner surface light brown, fracture fibrous, taste mucilaginous without any characteristic odour, it has no aerial roots (Paarakh et al., 2009; Kirtikar et al.,1975). The bark contains tannin, wax, saponin, gluanol acetate, cerylbehanate, lupeol, lupeol acetate, $\alpha \& \beta$-amyrin, gluanol acetate, $\beta$ sitosterol, stigmasterol and a ketone. Gluanol acetate and $\beta$-sitosterol have also been isolatated from the heartwood (Husain et al., 1992). Bark is efficient in threatened abortion, leprosy, urological disorders, dysentery, piles, diabetes, hiccough (Paarakh et al., 2009; Chopra et al. 1986; Vedavathy et al., 1995). The leaves are dark green, $7.5-10 \mathrm{~cm}$ long, ovate, in large clusters from old nodes of main trunk. Leaves contain glycoside, gluanol acetate, $\beta$-amyrin and $\beta$ sitosterol (Deep et al., 2013). The leaves are used in the treatment of ulcer, diarrhoea and dysentery (Deep

Correspondence to: Mst. Shirajum munira; Email: monira683382@ gmail.com; Phone: +8801717736803 
et al. 2013). As far our knowledge, no work has been found regarding the CNS activities of this plant. Present study has been undertaken to investigate the CNS activities of the crude extracts of $F$. racemosa in Swiss albino mice.

\section{Materials and Methods}

Plant material: The fresh fruits of $F$. racemosa Linn. were collected from Comilla, Bangladesh, 2017 and identified by an expert taxonomist. A voucher specimen No. DACB 45881 was given by the national herbarium, Mirpur, Dhaka, Bangladesh.

Preparation of the extract: About $650 \mathrm{gm}$ of dried and powdered plant materials obtained from the plants were soaked in 3.5 liter of methanol in an amber glass container for about 14 days at room temperature with occasional shaking. After 14 days, the solution was filtered using cotton filter and Whitman's filter paper number 1 . The filtrates were then concentrated to afford solid masses by using a rotary evaporator (Jeff et al.,1989; Haque et al., 2014), which was used for the experimental purpose.

Animals: Swiss albino mice (20-30 g) of either sex were purchased from the Animal Research Branch of the International Centre for Diarrhoeal Disease and Research, Bangladesh (ICDDR, B). The animals were housed under standard laboratory conditions. The animals were fed with laboratory food and water ad libitum. The experiments were done in an isolated and noiseless room.

Drugs and chemicals: Tween-80 was obtained from BDH Chemicals, UK. Normal saline solution was purchased from Beximco Infusion Ltd., Bangladesh. Diazepam and nortriptyline were obtained from Square Pharmaceuticals Ltd., Bangladesh.

Experimental design: The animals were randomly divided into four groups with each group consisting of four mice. The test groups received MFEFR (methanolic fruit extract of $F$. racemosa Linn) at the doses of 200 and $400 \mathrm{mg} / \mathrm{kg}$ body weight while positive control was treated with diazepam .

Open field test: The method described by Gupta et al. (Gupta et al., 1971) was slightly modified and used for screening depressive action of the test drugs on CNS in mice. The animals were divided into control and test groups. The test groups received methanolic fruit-extracts at the doses of 200 and 400 $\mathrm{mg} / \mathrm{kg}$ body weight orally, whereas the control group received vehicle (1\% Tween 80 in water). The floor of an open field of half square meter was divided into a series of squares where each alternatively colored black and white. The apparatus had a $40 \mathrm{~cm}$ height wall. The number of squares visited by the animals was calculated for $3 \mathrm{~min}$ on $0,30,60,90$ and $120 \mathrm{~min}$ subsequent to oral administration of the normal saline $(10 \mathrm{ml} / \mathrm{kg})$, experimental crude extracts $(200 \mathrm{mg} / \mathrm{kg}$ and $400 \mathrm{mg} / \mathrm{kg}$ b.w.) and diazepam as standard drug (1 mg/kg.).

Hole cross test: The method used was described by Takagi et al. (Takagi et al., 1971). The animals were divided into control, standard and test groups ( $\mathrm{n}$ $=4$ per group). The control group received vehicle $(0.9 \%$ saline in water at the dose of $10 \mathrm{ml} / \mathrm{kg})$ whereas the test group received extract (at the doses of 200 and $400 \mathrm{mg} / \mathrm{kg} \mathrm{b.w.)} \mathrm{and} \mathrm{standard} \mathrm{group}$ received diazepam at the dose of $1 \mathrm{mg} / \mathrm{kg}$ body weight orally. Each animal was then placed on one side of the chamber and the number of passages of each animal through the hole from one chamber to the other was recorded for 3 min on 0, 30, 60, 90 and 120 min during the study period.

Forced swimming test (FST): The FST is the most widely used pharmacological model for assessing antidepressant activity. This method is based on the observation of animals exposed to a situation of forced swimming, in which they become passive and immobile after a period of vigorous activity (struggling), producing only the movements required to keep their heads above the water. The FST was carried out on mice according to the method of Porsolt et al. (Porsolt et al., 1977). Swimming sessions were conducted by placing the animals in individual Plexiglas's cylinders ( $40 \mathrm{~cm}$ height, $24 \mathrm{~cm}$ diameter) containing $20 \mathrm{~cm}$ of water. The animals were treated with the extracts (200 and 400 $\mathrm{mg} / \mathrm{kg} / \mathrm{b} . \mathrm{w}$. orally), nortriptyline $(15 \mathrm{ml})$ or vehicle, $45 \mathrm{~min}$ before the test. All animals were forced to 
swim for $6 \mathrm{~min}$ and the time spent in immobility during the last $5 \mathrm{~min}$ of a $6 \mathrm{~min}$ observation period was recorded as immobile when floating motionless or making only those movements necessary to keep the head above water. A decrease in the duration of immobility during the forced swimming test is taken as a measure of antidepressant activity. This is recorded manually by the competent observer.

Tail Suspension test: The total duration of immobility induced by tail suspension was measured according to the method described by Sterut et al. (Steru et al., 1985). Briefly, mice both acoustically and visually isolated were suspended $30 \mathrm{~cm}$ above the floor by adhesive tape and placed approximately $1-2 \mathrm{~cm}$ from the tip of the tail. Immobility time was manually recorded during a 5 min period (Machado et al., 2017). Mice were considered immobile only when they hung passively or stayed completely motionless. Conventional antidepressants decrease the immobility time in this test. The animals were treated with the extracts ( 200 and $400 \mathrm{mg} / \mathrm{kg} \mathrm{b.} \mathrm{w.),}$ nortriptyline $(15 \mathrm{ml})$ or vehicle, $45 \mathrm{~min}$ before the test.

Statistical analysis: The results were expressed as the mean \pm SEM (standard error mean). ANOVA (analysis of variance) followed by Dunnett's ' $t$ ' test was performed as a post hoc test to evaluate the statistical significance while taking vehicle treated animals as control, $\mathrm{p}$ value of $<0.05$ was considered as statistically significant.

\section{Results and Discussion}

Open field test: In the open field test, it was found that, methanolic fruit extract of $F$. racemosa at the doses of $200 \mathrm{mg} / \mathrm{kg} \mathrm{b}$. w. and $400 \mathrm{mg} / \mathrm{kg} \mathrm{b}$. w. decreased number of hole crossed compared to the control group. Methanolic fruit extract exhibited a decrease in the movements of the test animals at all dose levels tested. The effect of the extract at the doses of $400 \mathrm{mg} / \mathrm{kg} \mathrm{b}$. w. significantly reduced the number to $76.25 \pm 6.60,68 \pm 3.25,53 \pm 3.83$ and 27 \pm 2.16 after $30 \mathrm{~min}, 60 \mathrm{~min}, 90 \mathrm{~min}$ and $120 \mathrm{~min}$ respectively. The depressing effect was most intense during the $3 \mathrm{rd}(90 \mathrm{~min})$ and 4 th $(120 \mathrm{~min})$ observation periods. The results are shown in table 1 .

Hole cross test: In the hole cross test, methanolic fruit extract of $F$. racemosa dose significantly decreased the number of hole crossed compared to the control group. Methanolic fruit extract of $F$. racemosa exhibited a decrease in the movements of the test animals at all dose levels tested. The depressing effect was moderately intense during the 3rd (90 min) and 4th (120 min) observation periods. The results are shown in figure 1.

Forced swimming test: In the forced swimming test, it has been found that, immobility time of extract at dose $200 \mathrm{mg} / \mathrm{kg}$ b.w. was similar to control. But at dose $400 \mathrm{mg} / \mathrm{kg} \mathrm{b}$. w. it was higher than control. After treatment with nortriptyline, immobility time was decreased. The results are shown in figure 2 .

Table 1. Effect of methanolic fruit-extract of $F$. racemosa on open field test in mice.

\begin{tabular}{|c|c|c|c|c|c|}
\hline \multirow[t]{2}{*}{ Treatment } & \multirow[t]{2}{*}{ Dose (mg/kg) } & \multicolumn{4}{|c|}{ Number of square crossed (minute) } \\
\hline & & After $30 \mathrm{~min}$ & $60 \mathrm{~min}$ & $90 \mathrm{~min}$ & $120 \mathrm{~min}$ \\
\hline Control & $0.1 \mathrm{ml} / \mathrm{mice}$ & $136.6 \pm 3.91$ & $115.25 \pm 5.52$ & $86.2 \pm 6.92$ & $90.25 \pm 7.43$ \\
\hline Diazepam & 1 & $88.75 \pm 4.5^{*}$ & $54.25 \pm 6.53^{*}$ & $19.5 \pm 4.5^{*}$ & $6.5 \pm 1.10^{*}$ \\
\hline MEFR 200 & 200 & $93 \pm 5.25^{*}$ & $75.25 \pm 6.13^{*}$ & $47.25 \pm 8.81^{*}$ & $33.25 \pm 3.99 *$ \\
\hline MEFR 400 & 400 & $76.25 \pm 6.60^{*}$ & $68 \pm 3.25^{*}$ & $53 \pm 3.83^{*}$ & $27 \pm 2.16^{*}$ \\
\hline
\end{tabular}

Values are presented as the mean $\pm \mathrm{SD}$ [SD=Standard Deviation]. $\mathrm{N}=4,{ }^{*} \mathrm{p}<0.05$ compared with control (One way ANOVA followed by Dunnet's test). MEFR = Methanolic extract of $F$. racemosa. 


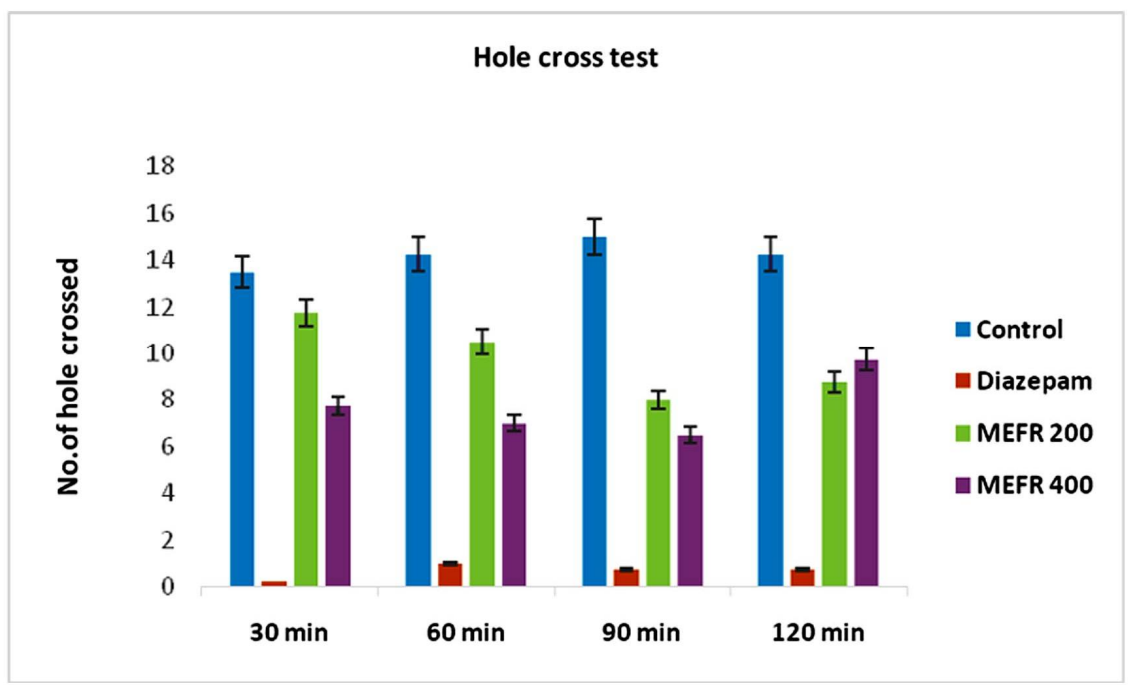

Figure 1. Number of hole crossed on hole cross test.

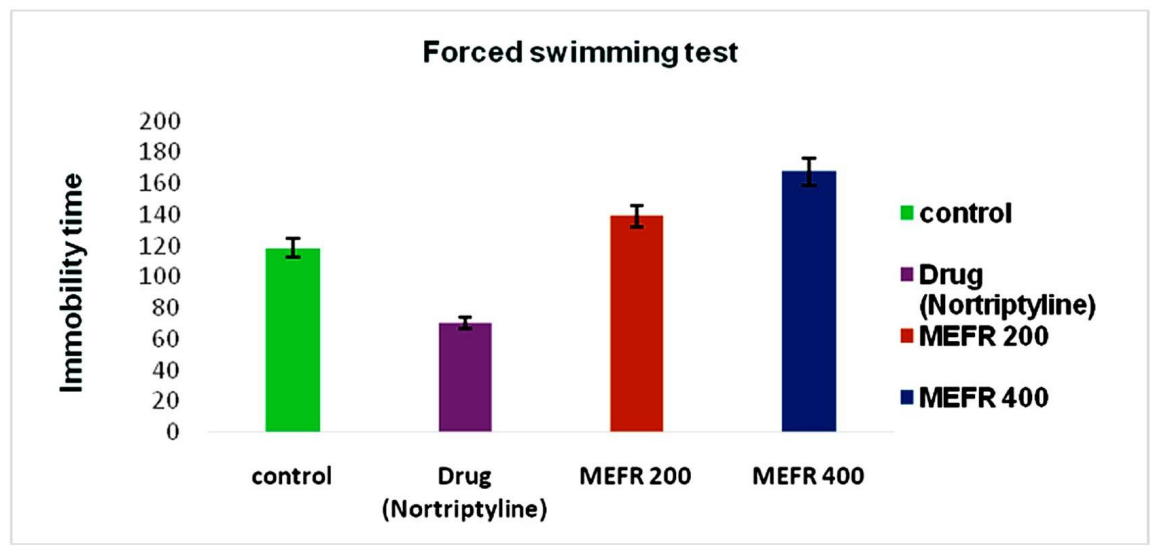

Figure 2. Immobility time on forced swimming test

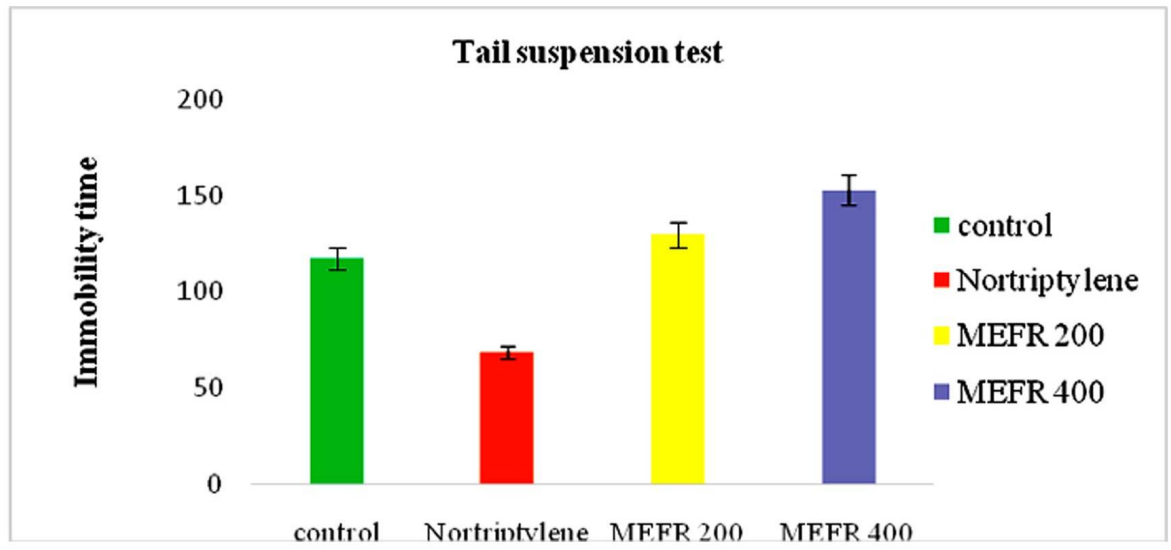

Figure 3. Immobility time on tail suspension test 
Tail suspension test: In tail suspension test, it has been found that, immobility time of extract at dose $200 \mathrm{mg} / \mathrm{kg}$ b. w. was comparable to control. But at dose $400 \mathrm{mg} / \mathrm{kg}$ it was higher than control. After treatment with nortriptyline, the immobility time was decreased. The results are shown in figure 3.

In the present study, the effect of methanolic fruit extract of $F$. racemosa on CNS has been evaluated. The result indicated that the extract significantly decreased locomotor activity which indicates its CNS depressant activity. Locomotor activity refers to an increase in alertness and decrease in locomotor activity considered as sedative effect. The major inhibitory neurotransmitter in the central nervous system is gamma-amino-butyric acid (GABA). Different types of anxiolytic, muscle relaxant, sedative-hypnotic drugs show their effects through GABA. The extracts of $F$. racemosa may act by membrane hyperpolarization, potentiating GABAergic inhibition in the CNS which leads to either decrease in the firing rate of critical neurons in the brain or direct activation of GABA receptor by the extracts (Khatun et al., 2011). Literature review of the plant reveals that $F$. racemosa contains terpenoids (Faiyaz et al., 2010), flavonoids, cyanogenic glycosides and tannin. Different types of flavonoids and neuroactive steroids were found to be ligands for the GABA receptors in the central nervous system, which indicate that they act as benzodiazepine-like molecules (Khatun et al., 2011). The pharmacological investigation of the methanolic fruit extract of $F$. racemosa was similar to diazepam which led to assume that they might interact with benzodiazepine receptor located adjacent to the GABA receptor.

\section{Conclusion}

Results of the present study indicate that all tested doses (200 and $400 \mathrm{mg} / \mathrm{kg} \mathrm{b}$. w.) of fruit extracts of $F$. racemosa exhibited significant sedative effect. The effect is dose dependent, long lasting and statistically significant. However, further investigation is needed to isolate the pharmacologically active compounds responsible for this activity.

\section{Acknowledgements}

The authors would like to thank Animal Research Division of the International Centre for Diarrhoeal Disease and Research, Bangladesh (ICDDR, B) for supplying mice and the National Herbarium of Bangladesh for identifying the plant sample.

Conflict of interest: Authors have no conflict of interest.

\section{References}

Aiyegoro, O.A. and Okoh, A. I. 2009. Use of bioactive plant products in combination with standard antibiotics: implications in antimicrobial chemotherapy. J. Med. Plants Res. 3, 1147-1152.

Chopra, R. N., Nayar, S. L. and Chopra, I. C.1986. Glossary of Indian Medicinal Plants (with Supplement), CSIR, New Delhi, pp.119-120.

Deep, P., Singh, K. A., Ansari, M. T. and Raghav, P. 2013. Pharmacological potentials of Ficus racemosa - a review. Int. J. Pharm. Sci. Rev. Res. 22, 29-34.

Faiyaz, A., Sharanappa, P. and Asna, U. 2010. Antibacterial activities of various sequential extracts of Ficus racemosa stem bark. Phcog. J. 2, 203-206.

Gupta, B. D., Dandiya, P. C. and Gupta, M. L. 1971. A psychopharmacological analysis of behavior in rat. Jpn. J. Pharmacol. 21, 293.

Haque, M., Jahan, T. and Rashid, M. A. 2014. Antibacterial and cytotoxic activities of Alocasia fornicata (Roxb.). Int. J. Nutri. Pharmacol. Neuro. Diseases 4, 29-33.

Husain, A., Virmani, O.P., Popli, S.P., Misra, L.N., Gupta, M.M., Srivastava, G.N., Abraham, Z. and Singh, A.K. 1992. Dictionary of Indian Medicinal Plants, CIMAP, Lucknow, India, 546.

Jeffery, G.H., Basse, J., Mendham, J. and Denney, R.C.1989. Vogel's textbook of quantitative chemical analysis. 5th ed. England: Longman Group UK Ltd. Chapter 6, pp.161.

Khatun, M. H., Islam, M. R., Mamun, A., Nahar, L., Luthfunnesa and Islam, M. A. U. 2011. In Vivo Evaluation of CNS Depressant and Antinociceptive activities of Methanol Extract of Hibiscus sabdariffa Fruits. J. App. Sci. Res. 7, 798-804. 
Kirtikar, K.R; Basu B.D. and Singh , B.S.M.P .1975. Ind. Med. Plants. $2^{\text {nd }}$.ed. . pp. 2327-2328.

Machado, D. G., Kaster, M. P., Binfaré, R. W., Dias, M., Santos, A. R., Pizzolatti, M. G. and Rodrigues, A. L. S. 2007. Antidepressant-like effect of the extract from leaves of Schinusmolle L. in mice: evidence for the involvement of the monoaminergic system. Prog. Neuro-Psychopharmacol. Biol. Psychiatry. 31, 421428.

Nadkarni K.M .1954. Indian Materia Medica, 3rd ed. Bombay ,Popular Prakashan. pp.2571-2575.

Paarakh P.M. 2009. Ficus racemosa Linn.-An overview. Nat. Prod. Radiance. 8, 84-90.

Porsolt, R. D., Le Pichon, M. and Jalfre, M. L. 1977. Depression: a new animal model sensitive to antidepressant treatments. Nature. 266, 730-732.
Sharma, S. and Gupta, V. 2008. In vitro antioxidant studies of Ficus racemosa Linn. root. Pharmacogn. Mag. 4, 70-74.

Steru, L., Chermat, R., Thierry, B. and Simon, P. 1985. The tail suspension test: a new method for screening antidepressants in mice. Psychopharmacol. 85, 367370.

Takagi, K., Watanabe, M. and Saito, H. 1971. Studies on the spontaneous movement of animals by the hole cross test: Effect of 2-dimethylaminoethane and its acyl esters on the central nervous system. Jpn. J. Pharmacol. 21, 797-810.

Vedavathy, S. and Rao, D.N. 1995. Herbal folk medicine of Tirumala and Tirupati region of Chittoor district, Andhra Pradesh. Fitoterapia. 66, 167-171. 